\title{
RECENT DEVELOPMENTS IN THE STUDY OF THE KIDNEY
}

\author{
By A. A. G. Lewis, B.Sc., M.D., M.R.C.P. \\ Physician to the Connaught, Chingford and Woodford Fubilee Hospitals
}

Within the last few years two techniques have been developed for the study of renal structure and function respectively and two startling theories, that are of very great interest and have important practical implications, have been put forward to account for the control of the renal circulation on the one hand and for the regulation of urinary dilution and concentration on the other. The following is neither a complete nor a critical review of these techniques and theories; it is intended to interest those who might not otherwise be fully aware of them and to serve as an introduction to a particularly fascinating field of theoretical speculation and practical investigation.

\section{Electron Microscopy of the Kidney (Rhodin, 1958)}

The electron microscope has revealed unexpected complexity in even the simplest renal structures, such as the glomerular membrane. The latter consists of three layers, being a continuous membrane sandwiched between an epithelial and an endothelial layer of cells, in both of which actual holes have been demonstrated. The epithelial cells have been termed podocytes as they apply innumerable foot processes, like suckers, to the basement membrane; processes from adjacent cells interdigitate, leaving spaces between which appear to be the ultimate filtering holes in the glomerular sieve, limiting the size of the molecules that can be filtered. Holes the size of a haemoglobin molecule have been demonstrated (Hall, 1957). The endothelial layer consists of flattened cells applied to the inner surface of the basement membrane, leaving perforations up to $1,000 \AA$ between them (this is the so-called fenestrated membrane).

The proximal tubule is formed by cells having two characteristics - a luminal brush border and basal lamellation. The former is composed of innumerable microvilli projecting into the tubular lumen, while the basal lamellae contain the mitochondria. These structures enormously increase the surface areas of the cells and this presumably increases the efficiency of reabsorption of substances from the lumen of the tubule and their $\vec{\omega}$ transport back into peritubular capillaries. The mitochondria appear to be intimately concerned $\mathbb{Q}$ with this process; during the reabsorption of large quantities of protein, or of abnormal protein, they of can be shown to swell into actual droplets.

The cells of the thin segment of Henle's loop appear to have a simpler structure than those of either the proximal or distal convoluted tubules. They are squamous in type, bulging into theo tubular lumen at the sites of the nuclei, an $\bar{\phi}$ having much smaller microvilli. The thin cytos plasm of each cell forms processes which inter $\$$ digitate with those of adjacent cells like those of the glomerular podocytes, though there appear tos be no actual ' holes' between them. The appearo $\overrightarrow{0}$ ance of these cells suggests a much simpler func $\leq$. tion than that of the proximal and distal con? volutions.

The distal tubular cells lack the brush borders of the proximal tubules, but have large numbers of prominent elongated mitochondria closely applied to basal lamellae, an arrangement again suggesting specialized reabsorption.

The collecting tubules are lined by both dark and light cells. The latter have far fewer granules in the cytoplasm and become increasingly more frequent in the distal parts of these tubules; they may be inactive lining cells.

The above brief description of some of the cellular structure revealed by the electron microscope shows that this is entirely consistent with our present views of renal function, namely, filtration-reabsorption, the glomerular filtrate containing some albumen (which is reabsorbed proximally) while reabsorption occurs along the whole length of the tubule, even in the collecting tubules. Electron microscopy has confirmed that there is always a lesion in the glomerular membrane in the nephrotic syndrome. Starting with loss of the foot processes of the podocytes, it extends to involve both the basement membrane and endothelial cells (Farquhar, Vernier and Good, 1957). 


\section{The Renal Circulation}

In 1947 Trueta and his associates published a stimulating monograph suggesting that, under certain circumstances, the blood flowing through the kidney might be largely diverted from the cortex through the juxta-medullary glomeruli, which differ from the others in having wider efferent arterioles which dip down into the medulla for variable distances as the vasa recta. This concept of a lesser circulation has not been upheld by renal function studies and is no longer tenable, though it cannot be denied that vasoconstriction is often unequally distributed between cortex and medulla, producing a much greater reduction of blood flow in the former. Like so many other discarded hypotheses, however, it led to a critical reappraisal of the problem of the control of the renal circulation from which other concepts have emerged. Any theory attempting to explain the mechanism of this control must take account of the phenomenon of autoregulation, which can readily be demonstrated in perfused kidneys. When the perfusing pressure is steadily increased, over a considerable range of pressures, little change in the renal blood flow occurs. There must either be some autonomous control of the tone of some important part of the renal vascular bed (since the organ has been denervated) or there must be changes in the effective viscosity of the blood flowing through the organ. Such changes might result from glomerular filtration; for example, the increased filtration at higher pressures slightly increasing the viscosity of the blood in the post-glomerular circulation. This change, however, would be too small to explain the phenomenon (Winton, 1956). Pappenheimer and Kinter (1956) have suggested that 'plasma skimming ' occurs in the kidney, plasma being preferentially removed from the blood in the inter-lobular arteries by those afferent glomerular arterioles which spring from them at right angles in the earlier part of their course, the more distally placed ones receiving a much greater proportion of the red cells. In the post-glomerular circulation, further plasma skimming is thought to occur, the cells being passed through short low-resistance channels into the venous system. This theory does offer an explanation of auto-regulation, since an increased perfusing pressure would increase the separation of plasma from cells and, therefore, also the effective resistance in those parts of the renal vascular bed receiving blood of relatively high haematocrit. It would also explain why autoregulation disappears when the haematocrit of the perfusing blood is very low. The theory is also compatible with the well-established fact that the haematocrit of the blood contained in the whole kidney is considerably less than that of aortic blood, red cells having been shown to traverse the organ more rapidly than plasma. However, there is no anatomical evidence of any widespread system of red cell shunts; the pathway that might be expected to divert them, that through the juxta-medullary glomeruli, evidently receives the plasma-rich moiety of blood. Criticisms of this theory have been made by Pitts and his associates (1958) and by Reubi (1958) on the grounds that anaemia does not increase the variation in the maximum rates of glucose excretion by different nephrons, as might be expected as plasma increasingly replaced cells in the blood perfusing cortical glomeruli.

Certainly it would be agreed that axial streaming of red cells occurs in the vasculature of the kidney, just as it does in many other vessels. This by itself would explain the more rapid passage of cells than plasma through the organ and the relatively low haematocrit of its content of blood. Whether or not any further separation than this occurs must remain extremely controversial, and it must be admitted that the plasma skimming theory raises almost as many difficulties as it solves.

These speculations about the control of the renal circulation are not merely of academic interest. Adjustments of renal blood flow to changes in the arterial haematocrit have long been known to occur, the plasma flow changing little unless anaemia or polycythaemia are very severe. Such an adjustment may fail to occur after transfusion of a patient with chronic renal disease, leading to an unexpected deterioration of renal function. Considerable changes in renal resistance must occur when the renal blood flow does not fall permanently after severe hypertension has been controlled by ganglion-blocking drugs (it must be remembered that renal denervation and spinal anaesthesia do not increase renal blood flow). In contrast, a very severe fall of renal blood flow follows severe haemorrhage or a reduction of cardiac output from other causes. Homer Smith (1956) cites a case of haemorrhage in which a fall of cardiac output from 5.3 to 3.751 ./min. led to a reduction of renal blood flow from 1,200 to 160 $\mathrm{ml}$./min. This type of renal vasoconstriction, with the accompanying failure of glomerular filtration, is largely responsible for the extra-renal uraemia that accompanies haemorrhage, dehydration, circulatory collapse and left ventricular failure.

\section{Glomerular Filtration}

Just as auto-regulation tends to stabilize renal blood flow in the face of changing arterial pressures, so it tends to stabilize the glomerular filtration rate (G.F.R.) when renal blood flow changes, by an alteration of the filtration fraction. The latter is therefore usually high when renal blood flow is 
reduced. This state of affairs occurs in congestive heart failure, when the filtration fraction may be as high as 0.6 (normally it is about 0.2 , one-fifth of the plasma water being filtered). It has recently been suggested (Malvin, Vander, Wilde and Sullivan, 1958) that in the proximal tubule water may be primarily reabsorbed under the influence of the osmotic pressure exerted by the plasma proteins in peritubular capillaries, sodium then moving across the tubule cells to maintain isotonicity. (This sequence of events is the reverse of that usually considered to occur.) When the filtration fraction is high, the proteins in the peritubular capillaries are more concentrated and more sodium and water will be reabsorbed. This provides a new explanation for the preternatural reabsorption of sodium in congestive heart-failure, which has not been convincingly explained either by the low G.F.R. usually (though not always) present or by the increased tubular reabsorption of sodium under the influence of aldosterone. One objection to this theory is the relative smallness of the changes in pressure that must be responsible for the very considerable changes in tubular reabsorption that occur.

\section{Tubular Function}

It is the remarkably selective and largely independently variable functions of the renal tubules that enable a normal human being to vary food and fluid intake between extremely wide limits with very little disturbance of body composition. The urinary solutes; for example, can be excreted with as little as $0.5 \mathrm{ml}$. or as much as $20 \mathrm{ml}$. of water per minute, implying a range of urinary concentration from about $1,400 \mathrm{mOsmol}$./1. down to 50 , or from nearly five times that of plasma down to less than one-fifth. These adjustments of urine volume can be made very rapidly by changes in the rate of anti-diuretic hormone secretion: faced with' the need to retain fluid the' organism can reduce the rate of urine flow from the maximum to the minimum within a few minutes; when needing to excrete water, maximum dilution can be attained in 'some 20 to 30 minutes and a litre of water excreted within four hours. The body cells are therefore protected against sudden wide fluctuations in the tonicity of their environment, the extra-cellular fluid; which would cause sudden changes in their own water content. When the kidney cannot vary the rate of excretion of water to preserve extra-cellular tonicity, cellular over-hydration may follow. This may occur if large volumes of water are drunk, or are given intravenously as glucose solution, after the in-. jection of pitressin tannate or in the hours following major surgery, or in Addison's disease.

It must be remembered that any increase in the quantity of unreabsorbed solute passing down the tubules must reduce the reabsorption of water from the glomerular filtrate and so increase urine volume. This is the mode of action of osmotic diuretics, such as urea. The large quantity of urea being filtered in each of the few remaining nephrons in advanced renal failure is probably. partly responsible for the polyuria and failure of urine concentration that occur in this condition.

Just as the concentration of the urine can normally be rapidly adjusted to changes in the organism's water requirements, so the reaction can be altered to preserve acid-base equilibrium. The change from $p \mathrm{H}_{4.5}$ to 8.0 is a three thousandfold change in hydrogen ion concentration, which can be effected very quickly by hyperventilation. (The change in the actual rate of excretion of hydrogen ions is, of course, quite different, since large quantities are buffered in acid urine; the amount excreted as hydrogen ion is negfigible.) The excretion of hydrogen ion is the result of a tubular ion-exchange process, sodium ions being reabsorbed from the glomerular filtrate and either hydrogen or potassiumi ions, from the interior of the cell, being exchanged for them. The hydrogen ion required for this exchange is derived from ionized intra-cellular carbonic acid, which is $\stackrel{\varnothing}{\varnothing}$ formed from dissolved carbon dioxide under the influence of carbonic anhydrase. A rise of p. $\mathrm{CO}_{2} \mathrm{O}$ in the body fluids accelerates this reaction and witho it the reabsorption of sodium, together with bicarbonate, while a fall of p. $\mathrm{CO}_{2}$ (as in hyperventilation) immediately inhibits it, potassium replacing hydrogen in the ion exchange and being excreted in the urine together with bicarbonate and an increased amount of unreabsorbed sodium. The same result follows the administration of $a$ carbonic anhydrase inhibitor, such as acetazolamide.

This linkage of sodium reabsorption with hydrogen and potassium excretion occasionally gives rise to anomalies of renal function. An alkaline urine cannot be formed unless cations (" fixed base') are excreted in place of hydrogen ions: ammonia is not formed to replace the latter in an alkaline urine (it is, in fact, formed to buffer hydrogen ions in an acid urine when it does enable cations to be conserved). In sodium depletion, when this ion is being almost completely reabsorbed, and in potassium depletion, hydrogen ion will be excreted even when there is alkalaemia, which will therefore be aggravated. This occurs after prolonged vomiting, in which sodium, potassium and hydrogen ions are all being lost from the E.C.F.; they cannot all be simultaneously conserved' by the kidney and the 'fixed bases' take preference.

The sodium concentration in the urine can also 
be adjusted within wide limits, from one barely detectable to one about twice that of E.C.F.; higher rates of sodium excretion are achieved without greater concentrations because an osmotic diuresis is produced. These adjustments are made more slowly than changes in the rate of water excretion and are largely affected by variations in the rate of secretion of aldosterone, probably as the result of changes in the volume of E.C.F. In severe sodium depletion the E.C.F. volume and cardiac output fall; there is renal vasoconstriction with a fall of G.F.R. and of the rate of filtration of sodium, with increased tubular reabsorption of the ion. Maximal sodium conservation is thereby achieved. A similar series of events follows the acute reduction of blood volume by severe haemorrhage.

Potassium is secreted into the urine by the distal tubular cells, all that filtered in the glomerulus being reabsorbed. The concentration in the urine may be many times that in the E.C.F., but conservation of this ion is less efficient than that of sodium in depletion.

In chronic renal failure it is the loss of flexibility of tubular function more than anything else that imposes limitations on the patient. In order to preserve the constancy of the milieu interieure, he must confine his protein and electrolyte intake within ever-narrowing limits. Theoretically, this can be done, until the ultimate limit is reached when the kidney cannot even remove the urea, potassium, hydrogen and anions produced by the catabolism of the minimum attainable quantity of endogenous protein. This is the state of affairs in anuria and in the oliguria of acute renal failure; it does not usually develop in chronic renal failure until more than 90 per cent. of the renal tissue has been destroyed. Until the urea clearance has fallen to about 5 per cent. of its normal value some variation in dietary intake can be dealt with; below this figure it becomes increasingly difficult for the patient to walk the biochemical tightrope imposed by his loss of renal function and to avoid severe acidaemia, hyperkalaemia and hypocalcaemia.

Recently the importance of a high blood level of urea itself in the genesis of uraemic symptoms has been demonstrated. A fact stressed by Platt (1952), this has been shown in dogs, in which a very high level of blood urea has been produced, without electrolyte disturbances, by peritoneal dialysis (Grollman and Grollman, 1959).

\section{The Regulation of Tubular Function}

Tubular control of the final elaboration of the urine cannot be fully effective if the load presented for tubular modification is very different from normal. Reduction of G.F.R. leads to some con- centration of the urine (Berliner and Davidson, 1957), while a great increase in the filtered load of solute leads to an osmotic diuresis, the urine increasing in volume while differing less and less from filtrate in its composition.

Normally, however, each of the three processes which the tubules control most precisely, namely, hydrogen ion secretion, sodium reabsorption and water reabsorption, though not independent of the other two, is regulated by an influence which can be rapidly adjusted for homeostasis. The rate of hydrogen ion secretion, which is linked with sodium reabsorption, is quickly altered by changes in intracellular $p \mathrm{H}$, particularly those brought about by changes in the $\mathrm{pCO}_{2}$ of body fluids. Changes in water reabsorption, which, taken together with those in sodium excretion, largely determine urine osmolarity, merit special consideration.

\section{The Mechanism of Urinary Dilution and Concentration (Homer Smith, 1958)}

The nature of this mechanism has always been of great interest, because the extremely wide and rapid variations that can occur in the concentration of the urine appear to imply equivalent changes in the rate of transport of water across specialized segments of the renal tubules, with the abrupt creation of extremely steep osmotic gradients.

The importance of the loop of Henle in the process of concentration of the urine was stressed by Burgess, Harvey and Marshall in 1933. They found that pituitary extracts produced a concentrated urine only in kidneys possessing loops of Henle-i.e. only in birds and mammals-and assumed that this was the site of action of the hormone. This appeared surprising in view of the apparently simple structure of the cells of this part of the tubule. Later, evidence gradually accumulated which indicated that concentration of the urine was one of the last tubular processes to occur and that it might take place in the collecting tubules. In his book on the kidney in I95 I Homer Smith accepted that the thin limb allowed rapid osmotic equilibration to occur between the fluid in the tubule and that surrounding it before the former entered the distal convolution for final modification. Analyses of fluid withdrawn from different parts of the nephron by tubular puncture have not supported either of these theories. In I94I Walker, Bott, Oliver and MacDowell showed, when the urine was hypertonic, that, whereas the fluid in the proximal tubule was isotonic, that entering the distal convolution was hypotonic. Later Wirz developed a beautiful technique for the puncture of both capillaries and tubules in the prominent papilla of the golden 


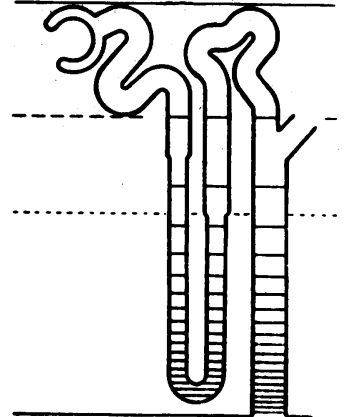

FIg. I.-Ciba Found. Symp. on The Kidney, (1954), p. 39. By kind permission of J. \& A. Churchill Ltd.

hamster's kidney, finding that in this region, which is, in fact, part of the inner medulla into which the loops of Henle descend, both the capillary blood and tubular fluid might be twice as concentrated as systemic blood (Wirz, r954). He suggested that the function of the loops was to create a hypertonic zone in the medulla into which water might be withdrawn from the fluid in the collecting tubules as they traversed it (Fig. I). This was produced, it was suggested, by the loops themselves acting as an instance of the counter-current system proposed by Hargitay and Kuhn (1951). It can be shown that when a solution is forced, under hydrostatic pressure, to flow round a U-tube whose limbs are separated by a membrane permeable to some of the solutes it becomes more concentrated near the bend of the tube. In the model illustrated in Fig. 2 an aqueous solution of a sodium compound fills the tube under a hydrostatic pressure $h$, $M$ being a cellophane membrane and $T$ a tap which at first is closed. Equilibrium is achieved when enough water has passed across $M$ from $a$ to $b$ to increase the osmotic pressure exerted by the sodium in $a$ until it balances $h$. If the tap T is now opened, $b$ is filled with the slightly more concentrated solution in $a$ and the process is repeated. In this way, at a certain optimum rate of flow, a high osmotic pressure can be developed around the bend in the tube; this is the principle of the counter-current multiplier.

This theory, which was not only of great theoretical interest, but was based on a very elegant technique, propounded a totally new conception of the functions of parts of the renal tubules at a time when it seemed that the great advance being made as a result of the introduction of clearance techniques by Homer Smith was coming to an end. In an excellent discussion of Wirz's work, Berliner, Levinsky, Davidson and Eden (1958) propose an alternative theory which is considerably simpler, though it disposes of the idea of the counter-current multiplier. The cells of Henle's loop are assumed to be always impermeable to

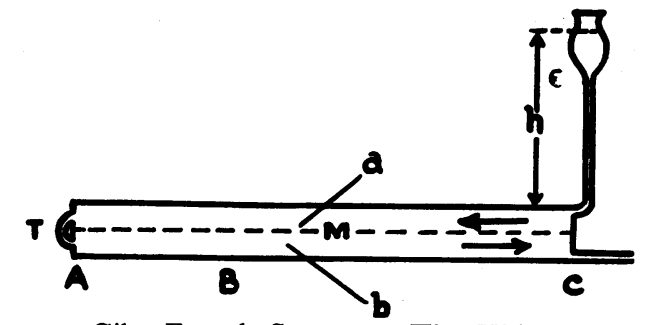

FIG. 2.-Ciba Found. Symp. on The Kidney, (1954), p. 42. By kind permission of J. \& A. Churchill Ltd.

water and to transport sodium actively from the thin segment; the surrounding zone therefore becomes hypertonic, while hypotonic fluid reaches the distal tubule, where further active solute reabsorption takes place. The assumption is made that the function of A.D.H. is to make the walls of the distal tubules and collecting ducts permeable to water, so that this is reabsorbed first in the former and then, to produce the final concentration of the urine, in the collecting ducts as they traverse the hypertonic medullary zone. In the absence of A.D.H. hypotonic fluid passes to the renal pelvis through impermeable tubules without further loss of water. The action of A.D.H. which is postulated, making the tubular epithelium permeable to water, is similar to that which it has been shown to exert on frogs' skin by Koeford-Johnsen and Ussing (1953).

It may be further assumed that in the final concentrating process urea is reabsorbed from the collecting tubule as well as water, a hypothesis supported by the finding of a high urea concentration on analysis of the renal papillary tissue (Ullrich and Jarausch, 1956). This would render the medullary zone even more hypertonic than it would become from the increased concentration of sodium alone, so allowing further urine concentration to take place. This is consistent with the finding that urine concentrations tend to be higher when urea is the principal urinary solute (Gamble, McKhann, Butler and Tuthill, I934; Miles, Paton and de Wardener, 1954) and with the known facts about urea clearance and urine flow.

Whether Wirz's original hypothesis, or recent modifications of it (Wirz, 1956; Ullrich and Jarausch, 1956), prove correct, it seems certain that the creation of a hypertonic medullary zone is essential for the occurrence of urinary concentration. Recent tubular puncture studies support Wirz's hypothesis (Gottschalk and Mylle, 1958). In any case, this zone cannot be created unless sufficient quantities of sodium and urea are delivered to it. If these fall greatly as a result of a reduction of the filtered load (produced by sharply reducing G.F.R.), then urinary concentration 
should fall. If an osmotic diuresis is induced during this fall of G.F.R. to maintain the high rate of delivery of sodium and urea to the loop of Henle and the distal tubule, this fall should not reduce urinary concentration. It has recently been shown that these are the changes that actually do occur in each case, provided G.F.R. is reduced by 30 per cent. or more (Levinsky, Davidson and Berliner, 1959). Analysis of the renal papillary tissue confirmed the expected changes in sodium and urea concentration.

Tubular concentrating power is therefore a much less fixed property of the kidney than was once thought. There is no evidence that it is limited by an osmotic ' ceiling.' It depends a great deal on variables such as the G.F.R. and the rate of excretion of solutes, particularly. of urea, as well as on the rate of secretion of antidiuretic hormone. Recently it has been shown that high protein diets or the administration of urea increase the maximum concentration of the urine in dehydrated subjects (Epstein, Kleeman, Pursel and Hendrikx, 1957), which is consistent with the theoretical considerations described above. Another interesting example of tubular adaptability of a different kind is the finding by these authors and by de Wardener and Herxheimer (1958) that maximum urinary concentration falls after a period of high water intake. This appears to be due to a decline in the response of the tubular cells to A.D.H., and may account for the thirst that develops after prolonged polydipsia (Kunstmann, 1933).

\section{The 'Stop-flow' Technique}

A new and interesting method for analysing tubular function has been developed by Malvin, Sullivan and Wilde (I957). When the ureter is clamped, pressure rapidly builds up behind the obstruction until filtration ceases. A column of fluid in each nephron is exposed to the modifications produced by the tubular cells; after a few minutes the clamp is released and rapid sampling of the fluid ejected from the ureter is carried out. The successive samples give an indication of events that have occurred along the length of the tubule during the arrest of flow. An osmotic diuresis is induced with mannitol to reduce distal tubular modification of the effluent, while an injection of inulin given just before release of the clamp serves to mark the arrival in the ureter of the newly formed filtrate. Variation in the times of flow through different nephrons and changes in the volume of the renal pelvis must obscure 1. some extent the pattern of tubular reabsorption and excretion, yet this technique will probably give much valuable information. Pitts, Gurd, Kessler and Hierholzer (1958) have used it to show that urinary acidification and marked sodium reabsorption occur together in the distal tubule at a site where potassium and ammonia are secreted. Malvin et al. (1958) investigated proximal sodium reabsorption, claiming that their data supported their suggestion that sodium and water were reabsorbed under the influence of the colloid osmotic pressure of the peritubular blood. More recently Malvin and Wilde (1959) have pointed out that the loss of urinary concentration noted during 'stop-flow' experiments is probably to be explained as the result of a failure of the countercurrent multiplier under these conditions. The gradient of sodium concentration along the length of the renal papilla normally produced by this system, which has often been demonstrated by analysis of serial tissue sections, and which is essential for concentration of the urine, disappears during an osmotic diuresis, presumably because the flow is too rapid. In the same way, the gradient must disappear if the flow ceases.

'Stop-flow' analysis is an entirely new technique which has yet to be evaluated. However, it is one of the new, stimulating lines of approach to the investigation of renal function that are leading to such rapid progress in our knowledge.

\section{BIBLIOGRAPHY}

BERLINER, R. W., and DAVIDSON, D. G. (1957), F. clin. Invest., 36, 1416.

BERLINER, R. W., LEVINSKY, N. G., DAVIDSON, D. G., and EDEN, M. (1958), Amer. भ. Med., $24,730$.

BURGESS, W. W., HARVEY, A. M., and MARSHALL, E. K. Jr. (1933) F. Pharm. and Exper. Therap. 49, 237.

EPSTEIN, F. H., KLEEMAN, C. R., PURSEL, S., and HENDRIKX, A. (1957), Ұ. clin. Invest., 36, 635 .

FARQUHAR, M. G., VERNIER, R. L., and GOOD, R. A. (1957), Amer. F. Path., 33, 791.

GAMBLE, J. L., MCKHANN, C. F., BUTLER, A. M., and TUTHILL, E. (1934), Amer. Э. Physiol., ro9, 139.

GOTTSCHALK, C. W., and MYLLE, M. (1958), Science, 128, 594. GROLLMAN, E. F., and GROLLMAN, A. (1959), $\mathcal{Y}$. clin. Invest., 38, 749.

HALL, B. V. (1957), Amer. Heart F., 54, r.

HARGITAY, B., and KUHN, W. (1951), Ztschr. Elektrochem., 55, 539.

KESSLER, R. H., HEIDENREICH, O. P. A., and PITTS, R. F. (1957), Amer. F. Physiol., r9r, 501.

KOEFORD-JOHNSEN, V., and USSING, H. H. (1953), Acta physiol. scand. 28, 60 .

KUNSTMANN, R. (1933), Arch. F. exper. Path., 170, 701.

LEVINSKY, N. G., DAVIDSON, D. G., and BERLINER, R. W. (1959), f. clin. Invest., 38, 730 .

MALVIN, R. L., SULLIVAN, L. P., and WILDE, W. S. (1957), The Physiologist, I, 58.

MALVIN, R. L., and WILDE, W. S. (1959), Amer. F. Physiol., 197, 177.

MALVIN, R. L., WILDE, W. S., VANDER, A. J., and SULLIVAN, L. P. (1958), Ibid., 195, 549.

MILES, B. E., PATON, A., and DE WARDENER, H. E. (1954), Brit. med.' F., ii, 901.

PAPPENHEIMER, J. R., and KINTER, W. B. (1956), Amer. $\mathcal{F}$. Physiol., 185, 377 .

PITTS, R. F., GURD, R. S., KESSLER, R. H., and HIERHOLZZER, K. (1958), Ibid., 194, 125.

PLATT, R. (1952), Brit. med. F., i, 1313.

REUBI, F. (1958), Helvet. med. Acta, 25, 516.

RHODIN, J. (1958), Amer. F. Med., 24, 66I.

SMITH, HOMER W. (r95I), 'The Kidney,' New York, O.U.P.

Bibliography continued on page $6 \mathrm{ro}$. 
tial inflammation also occurs and after repeated attacks the structural damage may be quite severe (Figs. 7 and 8). Long-term treatment with penicillin and short courses of steroids have not been found to prevent or shorten the attacks of haematuria.

\section{Conclusions}

Renal biopsy may occasionally be a considerable aid to diagnosis and prognosis in individual patients with glomerulonephritis. Frequently, however, the lesions revealed are either those that might be expected from a study of the clinical features or are insufficiently specific to give information of immediate value to the clinician. Further detailed studies with prolonged observation of the patients and the new techniques of electronmicroscopy, histochemistry and antigenantibody reaction localization (Mellors and Ortega, 1956) should lead to knowledge which will increase the value of the procedure.

\section{Acknowledgments}

I am grateful to Professor Clifford Wilson and Professor Dorothy Russell for permission to quote cases studied at the London Hospital and to reproduce microphotographs prepared in the Bernhard Baron Institute of Pathology.

\section{BIBLIOGRAPHY}

ALLEN, A. C. (1951), 'The Kidney: Medical and Surgicalo Diseases,' Grune and Stratton, New York, Ist ed.

ALLEN, A. C. (1955), Amer. F. Med., 18, 277.

BATES, R. C., JENNINGS, R. B., and EARLE, D. P. (1957), Ibid., 23, 5 10.

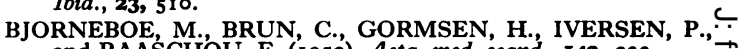
and RAASCHOU, F. (1952), Acta. med. scand., 142, 233. BRUN, C., GORMSEN, H., HILDEN, T., IVERSEN, P., and RAASCHOU, F. (1958), Ibid., 160, 155.

BRUN, C., and RAASCHOU, F. (1958), Amer. F. Med., 24, 676.

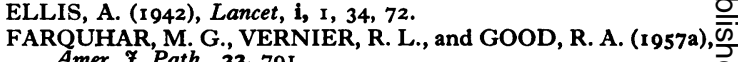
Amer. $\mathcal{F}$. Path., 33, 791.

FARQUHAR, M. G., VERNIER, R. L., and GOOD, R. A. (1957b), Schweiz. med. Wschr., 17, 50 .

FARQUHAR, M. G., VERNIER, R. L., and GOOD, R. A.ळ (1957c), Ұ. exp. Med., 106, 649.

FOLLI, G., POLLAK, V. E., REID, R. T. W., PIRANI, C. L., $\vec{\circ}$ and KÄR, R. M. (1958), Ann. intern. Med., 49, 775.

HUTT, M. S. R., PINNIGER, J. L., and DE WARDENER, H. E.w (1958), Quart. F. Med., 27, 265.

IVERSEN, P., and BRUN, C. (I951), Amer. F. Med., II, 324.

JOEKES, A. M., HEPTINSTALL, R. H., and PORTER, K. A. (1958), Quart. F. Med., 27, 495.

KARK, R. M., and MUEHRCKE, R. C. (1954), Lancet, i, 1047. KARK, R. M., MUEHRCKE, R. C., PIRANI, C. L., and POLLAK, V. E. (I955), F. clin. Invest., 34, 944 .

KARK, R. M., PIRANI, C. L., POLLAK, V. E., MUEHRCKE, R. C., and BLAINEY, J. D. (1958), Ann. intern. Med., 49, 751 ' LEITER, L. (193I), Medicine (Baltimore), 10, 135.

MELLORS, R. C., and ORTEGA, L. G. (1956), Amer. F. Path., $32,455$. MUEHRCKE, R. C., KARK, R. M., and PIRANI, C. L. (195-5,
F. Urol., 74, 267.

PEREZ ARA, A. (1950), Bol. Liga Cáncer (Habana), 25, 121.

RENNIE, J. B. (1947), Quart F. Med., 16, 21.

RICH, A. R. (1957), Bull. fohns Hopk. hosp., 100, 173.

ROSCOE, M. H. (1956), Quart. F. Med., 25, 253.

ROSS, J. H., and ROSS, I. P. (r957), Lancet, ii, 559.

ROSS, J. H. (1959), publication in preparation.

\section{NOTICE OF SPECIAL INTEREST TO SUBSCRIBERS:}

\author{
-WHY NOT HAVE YOUR COPIES OF THIS \\ JOURNAL BOUND INTO YEARLY VOLUMES?'
}

You can have your twelve monthly issues fully bound in dark green pin head doth. lettered in gilt on spine with name of Journal, Volume Number and year, complete with index at front, for 22s. 6d. post free. A limited number of out of prine fournals are available to bind into volumes and make your library complete. Price on application siving details of issues required to complete back volumes.

THE FELlOWSHIP OF POSTGRADUATE MEDICINe 60 PORTLAND PLACE, LONDON, W.I

\section{WHY NOT HAVE YOUR JOURNALS BOUND?}

Bibliography continued from page 603-A. A. G. Lewis, B.Sc., M.D., M.R.C.P.

SMITH, HOMER W. (1956), 'Principles of Renal Physiology,' New York, O.U.P. SMITH, HOMER W. (1958), Bull. N.Y. Acad. Med., 35, 293. REUBI, F. (1958), Helvet. med. Acta, 25, 516. RHODIN, J. (1958), Amer. F. Med., 24, 66r.

TRUETA, J., BARCLAY, A. E., DANIEL, P. M., FRANKLIN, K. J., and PRICHARD, M. M. L. (I947), 'Studies of the Renal Circulation,' Oxford, Blackwell.

ULLRICH, K. J., and JARAUSCH, K. H. (1956), Pflug Archiv. ges. Physiol., 262, 537.
VANDER, A. J., MALVIN, R. L., WILDE, W. S., and N SULLIVAN, L. P. (1958), Amer. $\mathscr{F}$. Med., 25, 497. S., and WALKER, A. M., BOTT, P. A., OLIVER, J., and MAC-N DOWELL, M.' (1941), Amer. F.'Physiol., I34 580. DE WARDENER, H. E., and HERXHEIMER, A. W. (1957),,$\omega$
F. Physiol., I39, 42.

WINTON, F. R. (1956), in 'Modern Views on the Secretion of the Urine,' London, Churchill. WIRZ, H. (1954), in the Ciba Foundation Symposium on the

WIRZ, H. (1956), in 'The Neurohypophysis,' London, Butter-? worth's Scientific Publications. 